\title{
PENILAIAN STATUS TROFIK LAGUNA SEGARA ANAKAN PADA MUSIM TIMUR DENGAN APLIKASI INDEKS TRIX
}

\section{ASSESSMENT OF THE TROPIC STATUS OF SEGARA ANAKAN LAGOON IN EASTERN SEASON USING THE TRIX INDEX APPLICATION}

\author{
Oleh \\ Rose Dewi $^{*}$, Taufan Harisam ${ }^{1}$, Rizqi Rizaldi Hidayat ${ }^{1}$, Hadi Endrawati ${ }^{2}$, Nur Laila \\ Rahayu $^{3}$, Abdal Seprianto ${ }^{4}$ \\ ${ }^{1}$ Fakultas Perikanan dan Ilmu Kelautan, Universitas Jenderal Soedirman \\ ${ }^{2}$ Fakultas Perikanan dan Ilmu Kelautan, Universitas Diponegoro \\ ${ }^{3}$ Fakultas Sains dan Teknologi, Universitas Nahdatul Ulama \\ ${ }^{4}$ Remote Sensing and Geographic Information System Technology Research, \\ Universitas Diponegoro \\ *Corresponding author : +6281327929555 \\ Email addres: rose.83unsoed@gmail.com
}

\begin{abstract}
ABSTRAK
Laguna Segara (LSA) terdapat disepanjang pantai selatan, bagian barat Jawa Tengah terletak pada ordinat $108^{\circ} 45^{\text {ee }}-109^{\circ} 01^{\text {ee }}$ BT and $7^{\circ} 35^{\text {ee }}-7^{\circ} 46^{\text {ee }}$ LS. Kawasan LSA memiliki karakteristik ekosistem yang berperan sebagai nursery ground, sehingga kajian produktivitas primer menjadi kajian yang sangat penting. Beragamnya aktifitas antropogenik dan faktor alami (sedimentasi) disekitar LSA, adanya pola angin musim (monsoon) mendukung perubahan ekologis. Kondisi tersebut dikhawatirkan berpengaruh terhadap penurunan produktivitas primer laguna, seiiring dengan perubahan status trofiknya. Tujuan kajian ini untuk mengestimasi status trofik yang dipengaruhi angin musim (monsoon) timur. Penilaian dilakukan menggunakan Indeks TRIX, guna mengevaluasi tren jangka panjang pola status trofik spasial LSA, dengan kombinasi linear log dari 4 variabel: Klorofil-a, aDO\%, Makronutrien (Total Nitrogen (TN) dan Total phospat (TP)). Pendekatan spasial dilakukan pada 7 stasiun (S) yang merepresentasikan: (S) faktor alam dan (S) aktifitas antropogenik. Penilaian indeks TRIX LSA menunjukkan, mayoritas melebihi 6 unit TRIX, yakni kategori perairan pesisir sangat produktif sehingga terjadi eutrofikasi, kondisi yang dapat menyebabkan anoksia pada perairan dengan diindikasikan tingginya kelimpahan fitoplankton jenis Habs. Tekanan antropogenik dan hidrodinamika perairan, diduga turut menyebabkan peningkatan makronutrien LSA yang memicu eutrofikasi. Diperlukan manajemen dan strategi pengelolaan laguna yang saling bersinergi antara Pemerintah daerah, pemangku kepentingan dan Masyarakat sekitar untuk meminimalisir fenomena eutrofikasi laguna.
\end{abstract}

Keywords : Laguna Segara Anakan, Status Trofik, Index TRIX, Klorofil-a, Makronutrien ABSTRACT
Segara Anakan Lagoon (LSA), located along the southern coast on western part of Central
Java, Indonesia $108^{\circ} 46^{\prime}-109^{\circ} 05^{\prime} \mathrm{E} ; 7^{\circ} 34^{\prime}-7^{\circ} 48^{\prime} \mathrm{S}$. It has an important ecosystem role as a
nursery ground, so that it is important to have further study of the primary productivity. The
antropogenic activities around the area, natural factors sedimentation and the monsoon 
wind pattern has changed the ecologys to the lagoon. Feared, it will influence the change in tropic status of the lagoon, and will cause the average degradation of the primary productivity value. The aim of the research is to explore the study of the primary productivity in Segara Anakan lagoon (LSA) with tropic status assessment, refers to the east monsoon wind pattern. Index TRIX has been used for evaluating long-term trend and spatial trophic pattern in the lagoon with linear combination of the log of 4 state variables: chlorophyll- $a$, aDO\%, macronutrient : Total Nitrogen (TN) and Total phospat (TP). The main objective of this study is to estimating tropic status. The spatial approach is done on 7 stations (S) with representations: (S) natural factors and (S) the presence of anthropogenic activities. Index TRIX assesment in LSA shows that point values, the majority exceeding 6 TRIX units are typical of highly productive coastal waters, where the effects of eutrophication determine frequent episodes of anoxia in bottom waters and indicated by high Habs phytoplankton. The anthropogenic pressure, aquatic hydrodynamics are thought to cause in the increasing of LSA macronutrients which trigger eutrophication of waters. Management and lagoon management strategies are required by the local government, stakeholders and communities to prevent the phenomenon of eutrophication of the lagoon.

Keywords : Segara Anakan Lagoon, Tropic Status Assesment, Index TRIX

\section{PENDAHULUAN}

Laguna Segara Anakan (LSA), secara geografis terletak pada ordinat $7^{0} 35^{\text {ee }}$ $7^{0} 46^{\text {ee }}$ LS dan $108^{0} 45^{\text {ee }}-109^{0} 01^{\text {ee }}$ BT di Kabupaten Cilacap, Jawa tengah. LSA diawali dari sebuah teluk dengan mulut laguna menghadap ke timur, Pulau Nusa Kambangan sebagai penghalang (barrier), memisahkan SAL dengan Samudra Hindia. Perubahan bentuk laguna hingga saat ini melalui berbagai tahapan ekologis. LSA merupakan kawasan yang tidak berdiri sendiri, berbagai faktor mempengaruhi perubahan ekologis kawasan (Ardli and Wolff, 2009; Carolita, 2005). LSA dipengaruhi input aliran air tawar dengan kuantitas tinggi, disertai sedimen tersuspensi, terutama dari S. Citanduy (Jennerjahn, et al., 2007). Sesuai pernyataan Holtermann, et al., (2009) S. Citanduy memiliki kontribusi catchment area sebesar $3,520 \mathrm{~km}^{2}$ atau memasok sekitar $80 \%$ aliran air menuju LSA.

Akumulasi bagian barat laguna, terutama terjadi pada musim penghujan, sedangkan bagian timur laguna didominasi hidrodinamika pasang surut dari Samudra Hindia (Jennerjahn et al., 2009). Aliran sungai membawa pasokan material organik terus menerus sehingga memicu proses konsolidasi sedimen dasar kawasan pesisir, sebagai sumber nutrisi dan pembentuk struktur fisik sedimen. Hal tersebut diketahui sebagai faktor alami yang mempengaruhi LSA.

Menurut Dewi, et al. (2016) sebagian besar volume badan air LSA digantikan dengan hutan mangrove, selanjutnya dikonversi untuk berbagai aktifitas antropogenik yang berpengaruh pada ekologis laguna. Ditunjang dinamika perairan secara kontinyu, menyebabkan terjadinya kompleksitas kontak fisika, kimia perairan maupun mikrobiologis yang memicu akumulasi konsentrasi unsur hara pada laguna. Kadarnya lebih tinggi dibandingkan laut lepas, sehingga produktivitasnya pun lebih tinggi (Dahuri et al.,1996).

Ditambahkan Dsikowitzky et al. (2011); Kennish (1992); Jennerjahn, et al,. (2009) bahwa sedimen yang berasal dari penggunaan lahan untuk aktifitas antropogenik akan mengandung unsur hara yakni makronutrien Nitrogen (N) dan Fosfat (P) yang terikat kuat dengan molekul air. Permasalahan tingginya sedimentasi, pertambahan jumlah penduduk, degradasi luas hutan mangrove untuk berbagai aktifitas antropogenik di 
LSA, mengakibatkan buangan unsur hara berlebihan (eutropic) ke badan air. Adanya kondisi tersebut menjadikan "eutrofikasi" pada LSA sangat penting untuk dikaji lebih lanjut.

Menurut Giovanardi and Vollenweider (2004) and Seisdedo, et.al (2014) bahwa penilaian terbaik untuk penentuan kategori status trofik pada perairan pesisir (coastal zone) termasuk pada perairan spesifik seperti laguna, dapat menggunakan Indeks TRIX. Eutrofikasi digambarkan dalam tingkat trofik sebagai nilai TRIX. Penggunaan indeks TRIX merupakan penilaian dari pengkayaan nutrien pada kondisi perairan spesifik seperti laguna (Pettine, et al., (2007); Bendoricchio (2005)).

Gejala pengkayaan unsur hara atau fenomena eutrofikasi, merupakan kategori status trofik yang dapat menimbulkan dampak negatif yakni degradasi perairan, terutama pada biota fitoplankton sebagai bioindikator kesuburan perairan. Fitoplankton mampu menunjukkan toleransi terhadap kondisi ketidakstabilan perairan, terutama saat terjadi peningkatan makronutrien $(\mathrm{N}, \mathrm{P})$ yang ditandai dengan perubahan dominansi spesies, struktur komunitas, biomassa ((Livingston (2001);
Coutinho, et al., (2012); Nielsen et al., (2004). Vadrucci, et al. (2013); Dewi, et al. $\left.(2017)^{\mathrm{a}}\right)$.

Ditambahkan Nontji (2008) berdasarkan data Meteorologi dan Oseanografi, bahwa perairan Indonesia dipengaruhi angin musim (monsoon), terdiri dari : musim Barat, musim peralihan I, musim Timur dan musim peralihan II. Pada musim timur (kemarau), perairan relatif sangat jernih, biru kehijauan. Hal ini diduga karena cukupnya intensitas cahaya matahari, didukung kualitas perairan lainnya mampu mendukung optimalitas kehidupan fitoplankton yang selanjutnya akan mempengaruhi kondisi trofik perairan.

\section{METODE PENELITIAN}

Penelitian dilaksanakan pada Pelawangan Barat LSA, Kabupaten Cilacap, (Gambar 1). Penentuan stasiun penelitan (spasial) merepresentasikan perbedaan karakteristik ekologis (Tabel.1). Representasi faktor alami pada stasiun (2, $3,4,6)$, sedangkan adanya pengaruh aktifitas antropogenik stasiun (1, 5, 7). Acuan penentuan lokasi penelitian tersebut selanjutnya digunakan sebagai pendekatan spasial.

Tabel. 1 Karakteristik Lokasi Pengambilan Sampel Penelitian di Kawasan Laguna Segara Anakan, Kabupaten Cilacap.

\begin{tabular}{|c|c|c|c|}
\hline Spasial & Karakteristik & $\begin{array}{l}\text { Koordinat Bujur } \\
\text { (Degree } \\
\text { MinuteSecond) }\end{array}$ & $\begin{array}{l}\text { Koordinat Lintang } \\
\text { (Degree Minute Second) }\end{array}$ \\
\hline S1 & TPI dan Pelabuhan Majingklak & $108^{\circ} 48^{\prime} 02.4 " \mathrm{BT}$ & $07^{\circ} 40^{\prime} 27.6^{\prime \prime L S}$ \\
\hline S2 & $\begin{array}{l}\text { Perbatasan Pintu masuk } \\
\text { (Pelawangan Barat) LSA yang } \\
\text { berbatasan langsung dengan } \\
\text { Samudra Hindia }\end{array}$ & $108^{\circ} 46^{\prime} 56.7 " \mathrm{BT}$ & $07^{\circ} 41^{\prime} 59.0^{\prime \prime L S}$ \\
\hline S3 & $\begin{array}{l}\text { Muara Sungai Cikonde dan } \\
\text { Cimeneng }\end{array}$ & $108^{\circ} 49^{\prime} 47.9^{\prime \prime} \mathrm{BT}$ & $07^{\circ} 40^{\prime} 34.6 " \mathrm{LS}$ \\
\hline S4 & Kawasan Hutan mangrove & $108^{\circ} 51^{\prime} 36.5^{\prime \prime B T}$ & $07^{\circ} 41^{\prime} 44.9^{\prime \prime L S}$ \\
\hline S5 & $\begin{array}{l}\text { Pemukiman } \\
\text { Kampung Laut }\end{array}$ & $108^{\circ} 52^{\prime} 14.0^{\prime \prime B T}$ & $07^{\circ} 42^{\prime} 19.5^{\prime \prime L S}$ \\
\hline S6 & $\begin{array}{l}\text { Kawasan Konservatif "Mina } \\
\text { Wisata "Ujung Alang, Kec. } \\
\text { Kampung Laut }\end{array}$ & $108^{\circ} 52^{\prime} 45.4^{\prime \prime B T}$ & $07^{\circ} 42^{\prime} 55.4^{\prime \prime} \mathrm{LS}$ \\
\hline
\end{tabular}




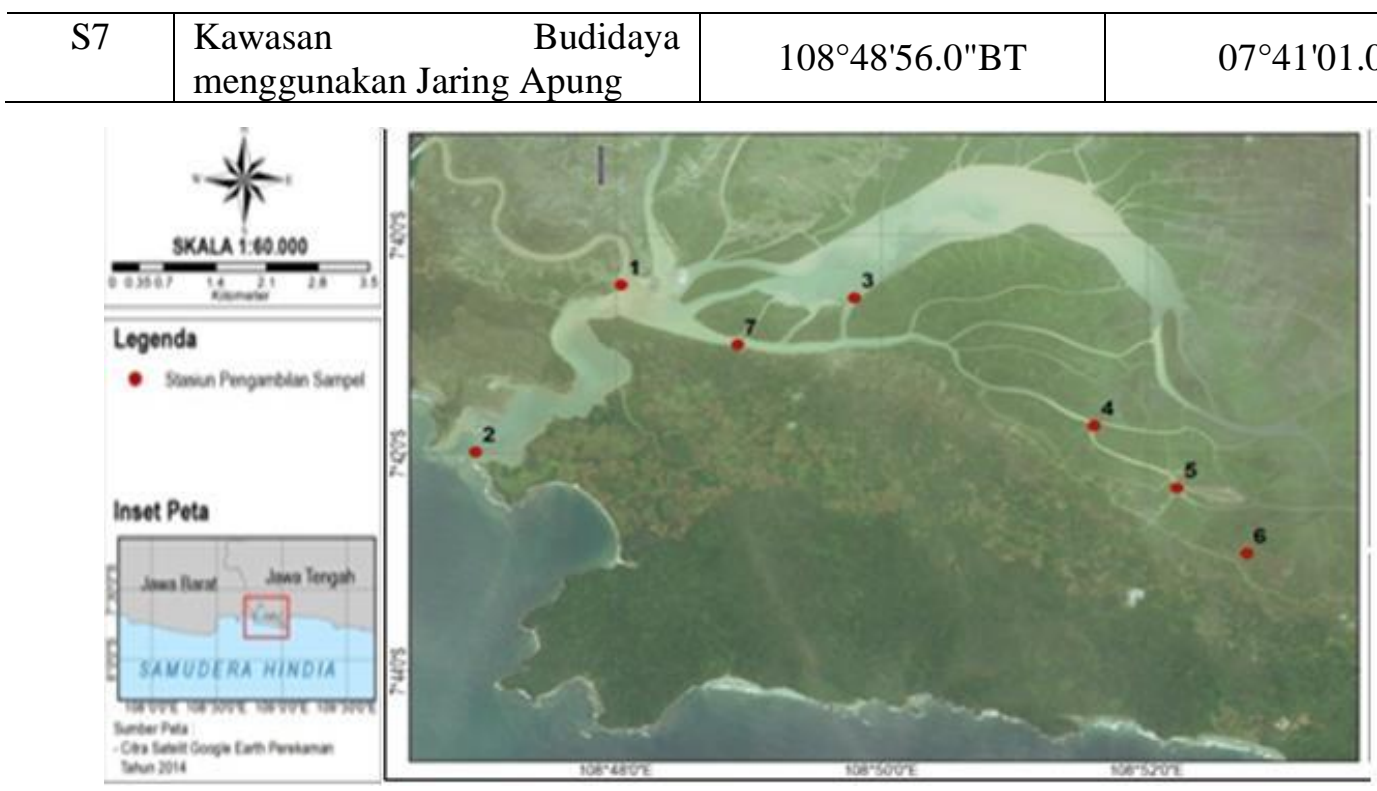

Gambar 1.Peta Lokasi Kawasan Laguna Segara Anakan, Kabupaten. Cilacap

Penentuan nilai status trofik perairan menggunakan indeks TRIX mengacu Giovanardi and Vollenweider (2004) dengan modifikasi kriteria konsentrasi nutrien sebagai penentu status trofik menggunakan TN, hal tersebut berdasarkan Vollenweider, et al. (1998) dan Smith, et al (1999) yang menggunakan kriteria TN dan TP sebagai penetu status trofik. Sehingga variabel ukur yang digunakan untuk perhitungan indeks TRIX dalam penelitian ini meliputi: $\mathrm{N}$ total, $\mathrm{P}$ total, \% DO, dan klorofil-a. Rumus perhitungannya adalah sebagai berikut:

TRIX $=\frac{(\log 10[\mathrm{ChA} \times \mathrm{DO} \% \times \mathrm{TN} \times \mathrm{TP}]+k)}{m}$

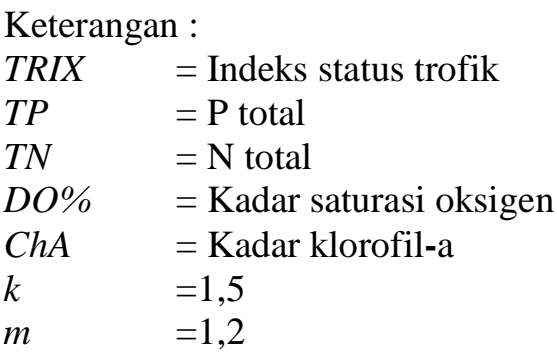

Pada penentuan kategori status trofik, indeks TRIX memiliki skala penilaian 010. Semakin tinggi nilai indeks TRIX menunjukan semakin tinggi tingkat eutrofikasi perairan. Kriteria indeks TRIX mengacu Giovanardi and Vollenweider (2004), dengan kisaran penilaian kategori pada (Tabel 2).

\section{Tabel.2 Kisaran Penilaian Status Trofik dengan Indeks TRIX}

\begin{tabular}{ccl}
\hline Kisaran & Kategori & \multicolumn{1}{c}{ Keterangan } \\
\hline TRIX $\leq 3$ & Rendah & Pada perairan laut terbuka \\
\hline $3,1 \leq$ TRIX $\leq 4$ & Sedang & $\begin{array}{l}\text { Nilai TRIX } \leq 4, \text { Pada perairan pesisir } \\
\text { yang hampir produktif. }\end{array}$ \\
\hline $4,1<$ TRIX $\leq 6$ & Tinggi & $\begin{array}{l}\text { Nilai TRIX 6 } \leq \text {, Pada perairan pesisir } \\
\text { yang produktif }\end{array}$ \\
\hline $6,1<$ TRIX $\leq 10$ & $\begin{array}{c}\text { Sangat Tinggi/ } \\
\text { meningkat }\end{array}$ & $\begin{array}{l}\text { Nilai TRIX 10 } \leq, \text { Pada perairan } \\
\text { pesisir yang sangat produktif, hingga } \\
\text { kadang ditemukan kondisi anoxia. }\end{array}$ \\
\hline $\begin{array}{l}\text { Pengukuran makronutrien Total } \\
\text { Nitrogen (TN) }\end{array}$ & $\begin{array}{l}\text { dengan metode Spektrofotometri } \\
\text { menggunakan metode }\end{array}$ & (APHA, 2005)
\end{tabular}

Mikro Kjeldahl; Total Fosfat (TP) 
- Pengukuran Oksigen Terlarut dan temperatur menggunakan Water Quality Checker (Merk Toa DKKJapan: Type WQC-22A), nilai DO\% diperoleh dari perhitungan antara kadar oksigen terlarut in-situ, oksigen teroritis pada suhu dengan tekanan $760 \mathrm{mmHg}$

- Pengukuran Klorofil-a dengan metode spektrofotometer (Hutagalung, et al., 1997)

- Pengambilan sampel air dilakukan secara vertikal, pada permukaan perairan laguna dengan kedalaman 0,5 - 1 m (APHA, 2005).

\section{HASIL DAN PEMBAHASAN}

\section{Variabel ukur perhitungan indeks TRIX}

Penentuan kategori status trofik Kawasan LSA, dalam penelitian ini menggunakan perhitungan kuantitatif indeks TRIX. Hal ini telah sesuai dengan Pettine, et al., (2007) dan Bendoricchio, (2005) bahwa dalam menentukan status trofik pada kondisi perairan spesifik seperti laguna, dapat menggunakan perhitungan kuantitatif indeks TRIX, yang merupakan penilaian dari pengkayaan nutrien. Selanjutnya ditambahkan Giovanardi and Vollenweider (2004); Seisdedo, et al (2014) bahwa penilaian terbaik untuk menentukan status trofik pada perairan pesisir (coastal zone) termasuk laguna yakni menggunakan Indeks TRIX. Karakteristik lain bahwa indeks TRIX dapat digunakan untuk membandingkan perbedaan spasial dan temporal status trofik pada suatu kawasan.

Variabel ukur indeks TRIX meliputi : TN, TP, \% DO, dan klorofil-a. Variabel tersebut menggambarkan tingkat kesuburan perairan. Menurut Setiapermana (2006) Total Nitrogen (TN) merupakan kadar nitrogen dalam badan perairan yang diperoleh dari penjumlahan: nitrat $\left(\mathrm{NO}_{3}\right)$, nitrit $\left(\mathrm{NO}_{2}\right)$, ammonium $\left(\mathrm{NH}_{4}\right)$, nitrous oksida $\left(\mathrm{N}_{2} \mathrm{O}\right)$, nitrogen dimolekular $\left(\mathrm{N}_{2}\right.$ terlarut), bahan organik mati (partikulat), bahan organik mati (terlarut), biomass mikroba, biomass hewan, biomassa tumbuhan. Nitrogen sebagai unsur terbesar udara dapat berdifusi dalam badan perairan melalui proses pengadukan. Kadar nitrogen yang berlebihan, dapat memicu gas disease organisme akuatik tingkat tinggi seperti memicu blooming fitoplankton (Vollenweider et al., 1998).

Total fosfat (TP) perairan diperoleh dari penjumlahan fosfat organik (berada dalam tubuh fitoplankton dan senyawaan organik) dan anorganik (orthofosfat, metafosfat atau polifosfat). Namun, fosfat anorganik hasil degradasi hanya dalam bentuk orthofosfat $\left(\mathrm{PO}^{3-}\right)$ yang terlarut yang dapat dimanfaatkan oleh organisme fotosintetik fitoplankton (Nielsen et al., 2004). TP merupakan jumlah semua bentuk senyawa fosfat yang mendorong terbentuknya eutrofikasi perairan (Nielsen, (2004); Zaaboub, (2014).

Prosentase kadar saturasi oksigen terlarut (\% DO) merupakan gambaran oksigen di perairan, berdasarkan perhitungan hubungan kadar oksigen terlarut in-situ dan oksigen teroritis pada tekanan 760 mmHg (Cole,1983). Diperjelas Vollenweider et al., (1998) bahwa kadar saturasi oksigen adalah \% kadar oksigen terlarut (DO) dibandingkan dengan oksigen teoritis pada suhu atau suhu tertentu. Parameter klorofil-a fitoplankton, digunakan sebagai indikator besaran organisme fotosintetik perairan. Deviasi kadar saturasi oksigen (\% DO) dan kadar klorofil-a dalam indeks TRIX menggambarkan produktivitas laguna. Sesuai dengan pernyataan Giovanardi and Vollenweider et al. (2004) bahwa indeks TRIX sebagai indeks multimetrik yang memberikan keuntungan memanfaatkan komponen variabel lingkungan yang langsung dapat terukur dan bahkan dapat dikumpulkan secara periodik.

\section{Penentuan Status trofik dengan Indeks TRIX dengan pendekatan spasial}

Berdasarkan hasil perhitungan kuantitatif status trofik Laguna Segara Anakan 
berkisar antara $0.7-9.3$. Menurut Giovanardi and Vollenweider (2004) Bahwa semakin tinggi nilai indeks TRIX, akan menunjukan semakin tinggi tingkat trofik suatu laguna. Adapun penilaian TRIX disajikan dalam (Tabel.3). Hasil menunjukan bahwa status trofik LSA tergolong dalam kategori rendah hingga sangat tinggi/ meningkat. Kategori tersebut menggambarkan adanya pengkayaan nutrien (eutrofikasi) di perairan LSA.

Tabel. 3 Hasil Perhitungan kuantitatif Indeks TRIX untuk penentuan Status Trofik Perairan Laguna Segara Anakan, Kabupaten Cilacap

\begin{tabular}{ccc}
\hline No. & Stasiun & Nilai Indeks TRIX \\
\hline 1 & S1 & 0.7 \\
2 & S2 & 1.4 \\
3 & S3 & 9.3 \\
4 & S4 & 8.9 \\
5 & S5 & 9.1 \\
6 & S6 & 8.4 \\
7 & S7 & 9.0 \\
\hline
\end{tabular}

Kondisi status trofik LSA menunjukan mayoritas stasiun penelitian berada pada kisaran $6,1<$ TRIX $\leq 10$. Menurut Giovanardi dan Vollenweider et al. (2004), nilai TRIX berada pada $6 \leq$, menunjukan bahwa kondisi perairan tersebut tergolong sangat produktif, hingga kadang ditemukan kondisi anoxia. Kondisi anoxia ini, dikhawatirkan akan berdampak negatif terhadap ekosistem. Pada kondisi anoxia, yakni menurun bahkan hilangnya oksigen pada badan air, sehingga dipersepsikan memberikan dampak negatif adanya degradasi perairan. Bahwa kondisi anoxia dapat ditandai dengan blooming fitoplankton yang berpotensi sebagai HABs, kematian massal ikan dan selanjutnya akan berdampak negatif dalam rantai makanan (Nontji, (2008).

Hasil tersebut sesuai pernyataan Livingston (2001) dan Dewi, et al. (2017) bahwa adanya pengkayaan unsur makronutrien $\mathrm{N}$ dan $\mathrm{P}$ (eutrofikasi) dalam kategori status trofik tinggi atau meningkat, dapat merangsang pertumbuhan fitoplankton dengan cepat blooming. (Dyer, K.R. 2000). Secara spasial stasiun penelitian (S1) terukur memiliki nilai TRIX tertinggi. Diduga pada (S1) didukung aktifitas antropogenik pelabuhan dan tempat pelelangan ikan (TPI), serta sebagai muara aliran air tawar dari sungai-sungai yang memasuki kawasan SAL dan berada tepat di belokan Sungai Citanduy menuju Samudra Hindia. Sesuai pernyataan Ayuningsih et al.(2014) dan bahwa kandungan TN akan semakin tinggi menuju pesisir dan tertinggi ditemukan di muara.

\section{KESIMPULAN}

Hal ini membuktikan bahwa adanya faktor alami sedimentasi dan antropogenik di sekitar LSA, menyebabkan akumulasi makronutrien pemicu eutrofikasi. Hal tersebut sesuai dengan pernyataan Jennerjahn, et al. (2009) $)^{\mathrm{b}}$ bahwa tinggi rendahnya kandungan makronutrien $\mathrm{N}$ dan $\mathrm{P}$ suatu perairan akan mempengaruhi kandungan klorofil-a yang terkandung dalam fitoplankton dan selanjutnya berpengaruh pada kelimpahannya.

Tingginya curah hujan akan berpengaruh terhadap tingginya fluktuasi makronutrien $\mathrm{N}, \mathrm{P}$; konsentrasi klorofil-a dan tingginya (\%) kelimpahan relatif fitoplankton yang berpotensi HABs. Pola curah hujan, merupakan pengontrol fluktuasi nutrien, secara signifikan berpengaruh terhadap fluktuasi $\mathrm{N}$ dan $\mathrm{P}$ sebagai faktor pembatas 
perairan yang selanjutnya mempengaruhi distribusi serta kuantitas klorofil-a. Bahwa perairan yang mengalami penyuburan (eutrofikasi) dapat terjadi karena adanya pelapukan bahan organik, buangan limbah daratan serta adanya perubahan musim. Pada daerah tropis, seperti Indonesia eutrofikasi dimungkinkan terjadi pada musim penghujan. Sehingga diperlukan managemen strategi pengelolaan laguna oleh Pemerintah Daerah setempat, pihak terkait dan masyarakat sekitar untuk menjaga kestabilan ekologis SAL, terutama terkait alih fungsi penggunaan lahan dan aktifitas antropogenik untuk meminimalisir fenomena eutrofikasi.

\section{UCAPAN TERIMA KASIH}

Trimakasih atas pendanaan Hibah BLU Lembaga Penelitian dan Pengabdian Kepada Masyarakat Universitas Jenderal Soedirman Tahun Anggaran 2019, yang telah mendukung pelaksanaan hingga terselesaikannya publikasi kajian riset ini.

\section{DAFTAR PUSTAKA}

[American Public Health Association (APHA). 2005. Standart Methods For The Examination Of Water And Waste water. 21 ${ }^{\text {st }}$ Edition. Edited By: Andrew. D Eaton, Lenore.S Clesceri, Eugene.W Rice, Arnold. E Greenberg. Centennial Edition. American Public Healt Association, American Water Work Association. Water Environment Federation. ISBN 0-87553-047-8, ISSN 55-1979

Ardli, E.R., and M. Wolff. 2009. Land use and land cover change affecting habitat distribution at Segara Anakan lagoon, Cilacap, Indonesia. Reg. Environmental Change. 9: 235-243

Ayuningsih, M.S, I.B. Hendrart and P.W. Purnomo. 2014. Distribution and
Abundance of Phytoplankton and Chorophyll-a in the Sekumbu Bay JeparaRegency: Relationship with Nitrate and Phosphate Content in Water. Diponegoro Journal Of Maquares. Manajement Of Aquatic Resources. Vol. 3, No.2. 138-147

Bendoricchio, G., De Boni, G., 2005. A water-quality model for the Lagoon of Venice, Italy. Ecological Modelling 184, 69-81.

Carolita, I, E. Parwati, B. Trisakti, T. Kartika dan G.Nugroho. 2005. Pendekatan prediksi perubahan lingkungan di Kawasan Perairan Segara Anakan. Pertemuan Ilmiah Tahunan MAPIN XIV. Pemanfaatan efektif penginderaan jauh untuk peningktan kesejahteraan bangsa. Institut Teknologi Sepuluh Nopember, Surabaya

Cole GA. 1983. Text Book of Limnology Third Edition. Waveland Press Inc. United States of America

Coutinho, M.T., A. C. Brito., P. Pereira., A.S. Gonçalves and M.T Moita. 2012. A phytoplankton tool for water quality assessment in semienclosed coastal lagoons: Open vs closed regimes. Journal Estuarine, Coastal and Shelf Science. 110: 134146

Dewi, R., M. Zainuri., S. Anggoro., dan T. Winanto. 2016. Analisis Perubahan Lahan Kawasan Laguna Segara Anakan Selama Periode Waktu (1978 - 2016) Menggunakan Satelit Landsat Multitemporal. Jurnal Omni Akuatika. 12 (3) : 144-14, 2016. Research Article. ISSN: 1858-3873 print/ 2476-9347 online

Dewi, R., M. Zainuri., S. Anggoro., dan T. Winanto. 2017 ${ }^{\mathrm{a}}$ Analisis Komposisi dan Kelimpahan 
Fitoplankton Secara Spasio-

Temporal Kawasan Laguna Segara

Anakan. Prosiding Seminar

Nasional Tahunan XIV. Hasil

Penelitian Perikanan dan Kelautan,

22 Juli 2017. Jilid II MSP.

Departemen Perikanan, Fakultas Pertanian, UGM.

Dewi, R., M. Zainuri., S. Anggoro., T. Winanto.,and Endrawati, H. 2017 ${ }^{\mathrm{b}}$. Characteristic and The distributtion of Spasio - Temporal Macronutrient in the Lagoon area of Segara Anakan. International Journal of Marine and Aquatic Resource Conservation and Co-existence. Research Article 2 (1): 51-57, October 2017. http://ejournal.undip.ac.id/index.php/ ijmarcc

Dahuri, R., J. Rais. S.P. Ginting, dan M.J. Sitepu. 1996. Pengelolaan sumber daya wilayah pesisir dan lautan secara terpadu. Pradnya Paramita, Jakarta: 305 hal.

Dsikowitzky,L, I. Nordhaus, TC. Jennerjahn, P. Khrycheva, Y.Sivatharshan, E.Yuwono, J. Schwarzbauer. 2011. Anthropogenic organic contaminants in water, sediments and benthic organisms of the mangrove-fringed Segara Anakan Lagoon, Java, Indonesia. Marine Pollution Bulletin 62. 851862

Dyer, K.R. 2000. Estuaries: A physical introduction (2 edition), John Wiley and Sons, New York, 195 pp

Giovanardi, F., and Vollenweider, R. A., 2004. Trophic conditions of Marine Coastal Waters: Experience in Applying the Trophic Index TRIX to Two Areas of the Adriatic and Tyrrhenian Seas. Journal of Limnology, 63(2), pp.199-218.
Jennerjahn, T.C.,_Holtermann., I. Pohlenga and B. Nasir. 2007. Environmental Conditions in The Segara Anakan Lagoon, Java, Indonesia. Synopsis of Ecological and Socio- Economic Aspect of Tropical Coastal Ecosystem With Special Reference to Segara Anakan.

Jennerjahn, T.C., B. Nasir, and I. Pohlenga. 2009. Spatio-temporal variation of dissolved inorganic nutrients related to hydrodynamics and land use in the mangrovefringed Segara Anakan Lagoon, Java, Indonesia. Reg Environ Change 9:259-274

Holterman P, Burchard H, and $\begin{array}{lll}\text { Jennerjahn } & \text { T.C. } & \end{array}$ Hydrodynamic of The Segara Anakan lagoon. Regional Environmental Change 9 (4), 245 258

Hutagalung ,H.P., D, Setiapermana., dan S.H, Riyono. 1997. Metode Analisa Air Laut, Sedimen dan Biota Buku 2. Jakarta: P3O-LIPI.

Kennish, M.J. 1992. Ecology of Estuaries: Anthropogenic Effect. Marine Science Series. CRC Press, Inc. ISBN: 0-8493-8041-3. Pp 492

Livingston, R.J. 2001. Eutrophication Processes in Coastal Systems. Origin and Succession of Plankton Blooms and Effect on Secondary Production in Gulf Coast Estuaries.. CRC Press LLC. Marine Science Series Boca Raton. Printed in the United State of America. ISBN. 08493-9062-1. Pp 327.

Nielsen, S.L, G.T Banta, and M.F Pedersen. 2004. Estuarine Nutrient Cycling: The Influence of Primary Producers. The Fate of Nutrients and Biomass. Aquatic Ecology Series. 
Vol.2. Kluwer Academic Publishers. Printed in the Netherlands. ISBN:14020-2638-2. Pp.303 Hlm.

Nontji, A. 2008. Plankton Laut. Jakarta: Lembaga Ilmu Pengetahuan Indonesia. LIPI Press. Jakarta. ISBN: 978-979-799-085-5. $331 \mathrm{Hlm}$. and Pagnotta, R. 2007. A Revisitation of TRIX for trophic status assessment in the light of the European Water Pettine, M., Casentini, B., Fazi, S., Giovanardi, F., Framework Directive: Application to Italian coastal waters. Marine Pollution Bulletin, 54 (9):1413-1426

Seisdedo, M., A.R Moreira., A.A Comas.,and G.Arencibia. 2014. Analysis of Tools For Tropic Status Assesment of Water in Cienfuegos Bay, Cuba. (PANAMJAS) PanAmerican Journal of Aquatic Sciences. 9(2): 103-111

Smith, V.H, Tilman GD, and Nekola JC. 1999. Eutrophication: impacts of excess nutrient inputs on freshwater, marine, and terrestrial ecosystems. Environ Pollut 100:179-196. doi:10.1016/S02697491(99)00091-3
Vadrucci, M.R., E. Stanca., C. Mazzioti, N. Ungaro and A. Basset. 2013. Ability of Phytoplankton trait sensitivity to tighlight antropogenic pressures in Mediteranean lagoons:A size spectra sensitivity index (ISSphyto). Ecological Indicators. 34: 113-125.

Vollenweider, R.A., F. Giovanardi., G. Montanari, and A. Rinaldi. 1998. Characterization of the Trophic Conditions of marine coastal waters with Special Reference to the NW Adriatic Sea: Proposal for a Trophic Scale, Turbidity and Generalized Water Quality Index. Environmetrics, 9(3), pp.329-357..

Zaaboub, N., A. Ounis., M. A Helali., B. Béjaoui., A.I. Lillebø., E.F. Silva and L. Aleya. 2014. Phosphorus Speciation in sediments and assessment of nutrient exchange at the water-sediment interface in a Mediterranean lagoon: Implications for management and restoration. Journal Ecological Engineering. 73 : 115- 125. 